\title{
A cura do corpo e a conversão da alma - conhecimento da natureza e conquista da América, séculos XVI e XVII
}

\section{Heloisa M eireles G esteira}

Os descobrimentos do século XVI, que ensejaram a montagem de impérios ultramarinos e 0 estabelecimento de rotas mercantis, foram responsáveis pela acumulação e divulgação de informações sobre a fauna e a flora americanas, freqüentemente diversas daquelas do Velho $M$ undo. 0 processo de colonização e conquista da América permitiu a ampliação do conhecimento que os europeus tinham sobre os produtos da natureza, possibilitou a introdução de espécies em ambiente distinto do original ea adaptação dos europeus aos trópicos. Estes considerados um lugar inóspito, de acordo com a herança de saber da antigüidade clássica.

Este conhecimento tornou-se imprescindível para garantir a permanência das novas sociedades que se constituíram a partir do processo de colonização. Controlar as informações desde as condições denavegação até as características das diversas regiões, identifican do suas peculiaridades físicas e climáticas, descobrindo novas espécies da flora e da fauna, observando as doenças endêmicas e os tratamentos realizados a partir dos produtos oferecidos pela natureza, foram práticas que possibilitaram 0 estabelecimento das novas sociedades no continente americano, desde 0 início de sua ocupação pelos portugueses e espanhóis, seguidos pel os franceses, ingleses e neerlandeses. Vale sublinhar que esse conhecimento era produzido por homens com formações diversas: cosmógrafos, teólogos, filósofos naturais, médicos, negociantes e missionários.

\section{Conhecimento da natureza e conquista da América}

As práticas medicinais oferecem um campo rico para nossa análise, uma vez que o conhecimento médico caracterizava-se, entre outros aspectos, pela descoberta das virtudes terapêuticas dos produtos naturais, mes- 
mo que em alguns momentos fossem evocados elementos sobrenaturais para restabelecer a saúde de um enfermo. ${ }^{1} \mathrm{C}$ abe lembrar que evocar 0 auxílio sobrenatural e atribuir significados transcendentes tanto à cura quanto aos objetos naturais não diminui o esforço na construção deum conhecimento, ainda mais no período por nós estudado, quando, como afirmou Robert Lenoble

A magia forma uma concepção da "N atureza", e esta $N$ atureza tem as suas "leis" e o conhecimento dessas leis dá-nos uma ciência certa e eficaz, pelo menos no sentido de ninguém duvidar das suas bases e de multidões inteiras, doentes curados, possessos libertos, artesão dos metais e fabricantes de tintas "verificarem" todos os dias o seu valor. ${ }^{2}$

A "botânica médica" aparece como um campo de saber privilegiado para a nossa análise, pois esse conhecimento era desenvolvido de forma sistematizada e, no caso específico da América portuguesa, controlado, sobretudo, por agentes sociais interessados na edificação de uma sociedade no N ovo M undo, entre os quais destacam-se os missionários da Companhia de Jesus. O s Jesuítas, apesar dos limites impostos por al guns dogmas católicos, não deixaram de observar, produzir eincorporar novidades científicas, mesmo que influenciados pela tradição clássica e pela Bíblia. O s colégios jesuíticos e al gumas universidades controladas pela ordem tornaram-se centros importantes de produção e difusão do saber não apenas na Europa, mas por todos os pontos do globo onde os inacianos levaram sua missão.

O pensamento científico do século XVII considerava a maneira pela qual D eus seapresentava no mundo natural um problema epistemológico, pois os objetos da natureza escondiam em sua essência os mistérios do C riador. O s sábios buscavam intensamente a identificação da atuação divina no U niverso, visando compreender a ação de D eus tanto no mundo natural como na história. I dentificar o al cance da atuação da Providência era também apontar os limites da ação humana no curso dos fenômenos. Em livro dedicado ao desenvolvimento desta problemática, AmosFunkenstein sugere al guns pontos essenciais para definir o que chama de uma teologia secular, assinalando as afinidades entre problemas científicos e religiosos durante o período. ${ }^{3}$ 
0 início dos tempos modernos foi marcado por uma transformação importanteem relação à cultura erudita da I dadeM édia, momento no qual decifrar os textos era o meio mais seguro para se chegar a Verdade. Cada vez mais, a experiência do ol har e a observação dos fenômenos tornavamse etapas importantes para a aquisição de conhecimento. $N$ esse sentido as grandes viagen oceânicas contribuíram significativamente para ampliar os horizontes culturais. 0 contato com o N ovo M undo possibilitou o confronto entre o saber tradicional eas novidades que vinham sendo observadas pelos viajantes ou pelos homens que, mesmo sem sair da Europa, podiam obter informações, as quaisos antigos não tiveram acesso. 0 sregistros produzidos pel os homens que entraram em contato com o $\mathrm{N}$ ovo $\mathrm{M}$ undo - direta ou indiretamente - contribuíram para fortalecer o movimento renascentista de crítica ao saber herdado da antigüidade, mesmo que este ainda fosse um referencial importante e exemplar.

Vistos em conjunto, percebemos esses movimentos de observação, coleta e sistematização do conhecimento sobre a natureza como um fenômeno ligado ao que Luis Filipe Barreto classificou como a "cultura dos descobrimentos", que se caracterizava por uma série de procedimentos práticos e teóricos diante das novidades. U ma das vertentes científicas que o autor analisou foi a medicina. Segundo Barreto "a medicina renascentista portuguesa é um dos mais ricos espaços da lógica cultural nacional, um dos mais profícuos e profundos domínios de afirmação da atividade espiritual e criativa dos portugueses do século XVI." ${ }^{4}$ As notícias e novidades sobre as terras distantes e desconhecidas eram controladas pelos agentes colonizadores e, quando consideradas estratégicas, eram mantidas sob sigilo, permitindo que o Estado controlasse um enorme "banco de dados". ${ }^{5}$

0 complexo e múltiplo jogo de interesses e valores que envolveu a expansão portuguesa expresso através das alianças e conflitos dos grupos sociais envolvidos - homens de negócios, missionários, nobres e os próprios agentes da Coroa - aliado ao fato de queo Estado português à época encontrava-seainda em processo de central ização, dificultava um controle "absoluto" por parte do poder central sobre a produção de conhecimento e troca de informações realizada no âmbito do Império luso. Pelo contrário, pode-se verificar uma certa dispersão no processo de acumulação de conhecimento, em particular ao relacionado à $\mathrm{N}$ atureza. Essa dispersão, 
porém, não deve ofuscar os esforços de alguns homens em sistematizar as informações, como atestam por exemplo os consagrados trabalhos de Pero $M$ agalhães de $G$ andavo, "H istória da Província deSanta C ruz", de G abriel Soares deSouza, "Tratado D escritivo do Brasil" eos de Ambrósio Fernandes Brandão "D iálogo das Grandezas do Brasil", para citar o mínimo.

N o caso específico da experiência portuguesa, sabemosqueas viagens propriamente científicas fomentadas pelo Estado intensificaram-se apenas a partir de meados do século XVIII, quando partiram expedições de Lisboa em direção aos pontos mais remotos do Império, resultando na produção de um conhecimento minucioso sobre as potencialidades naturaise populacionais controladas por Portugal. ${ }^{6}$ Ainda assim, não se pode menosprezar a atuação dos missionários da Companhia de Jesus e da própria O rdem Jesuíta na coleta e no controle de informações sobre a $\mathrm{N}$ atureza, em particular no campo de conhecimento que nos interessa: a botânica médica. Antes, porém, observemos o lugar de destaque que o serviço mé dico real izado pelos missionários jesuítas assumiu dentro dos interesses da Companhia de Jesus no mundo ultramarino.

\section{A cura e o projeto jesuítico na América}

0 controle do saber acerca da natureza refletia uma estratégia para a fixação da nova sociedadee manutenção da própria conquista. D esde 1549 - quando os primeiros missionários jesuítas desembarcaram na cidade de Salvador ao lado deTomé de Souza eguiados por M anuel da N óbrega - oS esforços físicos e intelectuais dos padres da Companhia, para edificarem sua obra, só foram interrompidos no momento de sua expulsão em meados do século XVIII.

O s jesuítas se estabeleceram rapidamente nos territórios conquistados pelos portuguesesnaÁfrica, naÁsia ena América. $\mathrm{N}$ as principaiscidadescoloniais ${ }^{7}$ construíram Colégios, locais essenciais para a difusão da obra jesuítica. Em cada ponto importante da América portuguesa os jesuítas ergueram igrejas, capelas, colégios, casas, seminários, aldeias, fazendas, currais e engenhos, enfim, uma série de recintos que, articulados entre si, ofereciam uma base de sustentação e de propagação da mi ssão evangelizadora: salvar o gentio convertendo-o ao catolicismo, assegurando, assim, a 
expansão da fé. No entanto, os soldados de cristo não se descuidaram da tarefa de expandir o império, pois a aliança com a coroa portuguesa garantia, entre outras coisas, a presença da Companhia pelos quatro continentes.

Os Colégios situados em Salvador, O linda e Rio de J aneiro - principais centros da conquista lusa na América desde o século XVI - representavam uma espécie de cidadela "Ietrada", ${ }^{8}$ onde os missionários da Companhia delineavam estratégias que buscavam a expansão dafée do império, além de receberem as ordens vindas de seus superiores através de uma complexa rede epistolar. D entre as várias funções dos Colégios, queremos focar o cuidado médico com a população circunvizinha, composta por portugueses, escravos da Guiné e índios, e o estabelecimento de um locus de produção de conhecimento. Vale lembrar que outros locais importantes para o projeto jesuítico, como as fazendas eal deias, eram também dotados de hospitais e contavam com boticas providas de medicamentos.

0 cuidado médico era visto como um dos serviços importantes que os jesuítas ofereciam à manutenção do império. No início do século XV II, quando o padreFernão Guerreiro publicou em Évora sua obra divulgando as conquistas realizadas pela Companhia de Jesus por todo o império ultramarino português, assim assinalou a importância das missões jesuíticas no Brasil:

Porque não somente os curam nas almas como pastores (...), mas os padres os governam ainda no temporal elhes dão ordem de como hão de negociar suas roças e lavouras e remédios de vida quando estão doentes, os padres são os seus médicos e enfermeiros, $(. . .)^{9}$

Ainda confirmando o valor estratégico da cura, observemos o conteúdo de um traslado dealvará régio, de 1641, guardado no Livro deTombos do Colégio de São Sebastião do Rio de Janeiro:

Eu El-R ey faço saber aos que este alvará virem que tendo consideração ao que me representou por parte de Paullo da Costa, religioso da Companhia de Jesus, procurador da Província do Brasil, e ao que constou em razão dos serviços que os religiosos da dita Companhia daquele Estado me tem feito (...) em tudo o que nele se tem oferecido (...), como nas ocasiões de guerra a que sempre assistiram com as pessoas, escravos efazendas, acudindo com os índios de suas doutrinas assim aos trabalhos das fortificações (...) princi- 
palmente todo o tempo que o inimigo teve ocupada a Bahia assistindo a tudo sem faltar nunca ao arraial, administrando os sacramentos, pregando, animando e ao serviço de $D$ eus e meu, tomando a sua conta as enfermarias e acudindo aos doentes com os remédios espirituais e corporais. (... $)^{10}$

Em troca desses serviços prestados, informa o alvará mais adiante que a Companhia recebia al guns privilégi os tais como o direito de cobrança da redízima, a isenção de imposto na alfândega, a manutenção de propriedades fundiárias ainda sem uso e o recebimento de doações e esmolas para o sustento desua obra. 0 importante para a nossa argumentação éa menção aos serviços médicos prestados pelos jesuítas, sobretudo os remédios corporais que eram oferecidos aos homens. Falando do Estado do Brasil em meados do século XVII, não parece irrelevante o reconhecimento real da importância dos medicamentos manipulados pelos jesuítas, pois a escassez de profissionais da saúde fora um problema concreto para aquela sociedade assolada por guerras freqüentes e com uma natureza repleta de elementos desconhecidos, entre eles os animais peçonhentos.

O s serviços médicos aparecem, portanto, como uma moeda de troca que permitia à Companhia de Jesus receber favores e privilégios do monarca em terras americanas. ${ }^{11}$

0 papel de médico e de enfermeiro assumido pelos missionários poderia ser visto apenas como caridade. Entretanto, assume um contorno político importante quando lembramos a autoridade que os homens que curam exercem sobre os demais, desde os tempos mais remotos e em culturas diversas. Reiterando essepapel do missionário, há uma passagem que nos parece bastanteel oqüenteescrita pelas mãos de quem lidou diretamente com o gentio nas missões, o padre José de Anchieta:

U ma criança de quatro ou cinco anos de idade, assal tada de grave enfermidade, rogava muitas vezes em pranto à mãe que a trouxesse ao Templo, ea mesma criança, gemendo diante do altar, dizia na sua própria língua: "Ó Padre, cura-me!" Esta, interrogada por seu pai, se porventura queria quelhe chamassem aquel efeiticei ro para lhe aplicar o remédio, chorando com grandes lamentos lançou-se por terra, dizendo que não com ele, mas com o auxílio de D eus Ihe seria restituído o antigo vigor: o que o mesmo Senhor operou, pois, aplicado pelos nossos irmãos um certo remédio, recobrou a tão esperada saúde. ${ }^{12}$ 
0 trecho de Anchieta deixa transparecer aspectos importantes. 0 primeiro équea busca pelo socorro médico confunde-se com a busca pelo socorro espiritual. 0 par "espiritual" e "temporal" forma um dos tópicos centrais dos textos do missionário, que além dos sacramentos ministrou serviços médicos entre o gentio, como tantos outros padres que deram continuidade à missão jesuítica até 0 século XVIII. Entre as tarefas do Padre José de Anchieta, a cura das doenças que afligiam os nativos aparece logo em seguida à conversão. 0 auxílio médico transformou-se numa das estratégias para os missionários conquistarem a alma indígena, contribuindo assim na transformação destes homens em verdadeiros cristãos.

Cuidar dos índios enfermos curando-os das moléstias transformouse, conforme análise de JoséE Eisenberg num "dos instrumentos de conversão". As dificuldades encontradas na tarefa de converter os índios fizeram com que os jesuítas buscassem novos métodos para auxiliar no trabal ho da catequese. A cura de doenças como auxiliar na tarefa missionária surgiu na experiência cotidiana experimentada pelos padres no território americano. Segundo José Eisenberg, quando os jesuítas perceberam que

os índios conferiam autoridade religiosa ao curandeiro da tribo, (...) tentaram assumir esse papel, e, para competirem com a autoridade religiosa dos pajés, começaram a se dedicar ao atendimento médico dos índios eadaptar os rituais dos sacramentos cristãos aos usos locais. ${ }^{13}$

A preocupação em assumir a responsabilidade pela saúde do gentio seria uma novidade introduzida pel os primeiros inacianos que vieram, intensificando-se a partir da chegada de José de Anchieta, que se destacou pelos serviços médicos realizados em suas atividades. A arte de curar, na tradição Tupi, estava associada à capacidade daquele indivíduo se comunicar com osespíritos. O smissionários concluíram quepara sua palavraatingir de fato o coração dos índios e, chegar ao fundo de sua alma, eles teriam que evidenciar o privilégio da comunicação com os espíritos, "e isso colocava os irmãos em direta competição com os pajés." ${ }^{14} 0$ s missionários lutaram para retirar dos pajéso seu poder de cura, labutando para conquistar o corpo e a alma dos indígenas, mantendo-os vivos, de modo a garantir a expansão da fé e do império. Tal atitude colaborou para que os pajés fossem sempre associados à imagem do feiticeiro que agia em nome do de 
mônio, mesmo que estes realizassem práticas muito próximas àquelas implementadas em nome de D eus, como a administração de símplices e realização de sangrias, além dos recursos sobrenaturais, amuletos e rezas.

Pode-se perceber a resistência dos íncolas aos tratamentos impostos pelos missionários, principalmente a utilização de produtos compostos ${ }^{15}$ - típicos da medicina experimental européia de então - como bem observou Simão de Vasconcelos:

Em suas curas ri-se esta gente de medicamentos compostos: só nos simples dos campos têm sua confiança: eestes Ihes ensinou a natureza, eo uso, como a arte aos mel hores médicos; cada qual é médico de si, e dos seus; e aplicam com grande destreza os remédios, assim interiores como exteriores, especialmente contra venenos. ${ }^{16}$

O s remédios compostos por várias substâncias naturais (vegetal, animal e mineral) eram estimados na terapêutica européia dos séculos XVI e $X V I I$, e suas receitas valiosas, como atesta a famosa fórmula manipulada pelosjesuítas, a Triagra Braślica, que

hé um Antídoto ou Panacea composta, à imitação da Triagra de Roma e de Veneza, devárias plantas, raízes, ervase drogas do Brasil, quea natureza dotou detão excellentes virtudes, que cada huma por si só pode servir em lugar da Triagra da Europa; pois com al gumas das raízes, de que compõe este Antídoto, se curão nos Brazis de qual quer peçonha e mordedura deanimais venenosos, como também de outras várias enfermidades, só como mastigá-llhas. ${ }^{17}$

O s 27 produtos utilizados nesta receita eram quase todos originários ou cultivados na América, exceto as raízes deacoro, de aristoloquia redonda, de junça e de malvaisco, vindas de Portugal, conforme indicado na composição. V ários produtos tais como as raízes de jaborandi, de pagimiroba e cipó de cobra eram encontrados na quinta do Collégio da Bahia. Q uem anotou a receita teve o cuidado de informar o lugar onde os ingredientes poderiam ser adquiridos, nas quintas dos Colégios, residências e aldeias jesuíticas, nas regiões já conquistadas ou, simplesmente, no "sertão". A Triagra Braślica foi uma das fórmulas que renderam dinheiro para o Colégio da Bahia.

O s jesuítas foram responsáveis pela circulação de espécies naturais e de práticas medicinais não apenas no âmbito da América portuguesa, mas 
no interior do I mpério português. Além disso, trocavam experiências com seus confrades ligados a outras assistências daC ompanhia, como por exemplo entre os missionários das províncias jesuíticas da América espanhola, prática intensificada durante a União Ibérica. A troca dava-se em vários sentidos simultaneamente. $0 \mathrm{~s}$ padres farmacêuticos, aqueles que eram encarregados da manipulação de medicamentos nas boticas, procuravam utilizar produtos locais para composição de suas fórmulas, uma vez que a comunicação com a Europa era muitas vezes lenta e irregular. Para descobrir as qualidades de determinadas ervas, um dos procedimentos utilizados era observar 0 uso que os habitantes locais faziam delas. 0 que nos importa assinalar, éque, na América portuguesa, ao coletar os dados medicinais, os ungüentos, as ervas eas partes deanimais utilizadas nas mezinhas, os jesuítas catalogaram os costumes indígenas e suas práticas terapêuticas.

0 movimento decoleta eincorporação de terapêuticas locais por parte dos missionários jesuítas foi observado por Ana M aria Amaro estudando as fórmulas utilizadas na botica do Colégio de São Paulo, em M acau. A autora verificou uma grande influência da medicina chinesa no receituário dos inacianos que atuaram na região. Portanto, os padres da Companhia de Jesus foram agentes importantes da circularidade cultural, pois a constante troca de missivas contendo informações as mais diversas, gerou uma cosmopolitização das receitas e de práticas medicinais pelos quatro cantos do mundo, como veremos em alguns exemplos mais adiante. ${ }^{18}$

Um belo exemplo da ação jesuítica no que diz respeito à coleta e ao controle sobre o conhecimento ligado à medicina é o livro manuscrito, organizado em Roma por um jesuíta português, datado de 1776, cujo título é Colleção deVárias Receitas e Segredos Particulares das Princi pais Boticas da N ossa Companhia de Portugal, da Índia, de M acau e do Brasil. Compostas e experimentadas pelos mel hores médicos e boticários. 0 livro forma um conjunto rico em informações sobre as potencialidades dos produtos da natureza nos vários pontos do globo por onde os inacianos edificaram sua obra, em particular no âmbito do império português.

A té o momento tratamos da cura como uma estratégia de catequese jesuítica. C abe agora analisar algumas práticas que demonstram tanto a sistematização desse conhecimento, quanto as possíveis concepções médicas compartilhadas pelos jesuítas. 0 recolhimento das informações sobre 
as virtudes das plantas e de al gumas partes de animais para uso medicinal foi feito de maneira sistemática, o que levou os jesuítas a acumularem um saber importante para a manutenção da sociedade colonial. Por isso, as boticas situadas em todos os Colégios aparecem como um espaço privilegiado para a produção desse conhecimento, uma vez queali as plantaseram transformadas em mezinhas etisanas que seriam distribuídas, se o necessitado fosse pobre, ou vendidas se o enfermo fosse abastado.

\section{A conquista do mundo natural}

(...) leva essas conservas para os enfermos, os ananases para dor de pedra, os quais posto não tenham tantas virtudes como os verdes todavia fazem proveito. O s I rmãos que lá houvesse desta enfermidade, deviam vir para cá, porque se achariam bem aqui, como se tem por experiência. ${ }^{19}$

Trechos com este podem ser encontrados freqüentemente na correspondência dos missionários, mesmo em cartas que tratavam de outros assuntos. Paral elamente havia outro tipo de referência de forma sistematizada, evidenciando o propósito de acumular informações. A diferença entre asinformações dispersas e o registro sistematizado éque particulariza aquilo que consideramos como "produto das viagens".

D enominamos produto das viagens todo o material elaborado a partir das informações que chegavam ao continente europeu nos navios que regressavam do ultramar. Por suas características, os produtos das viagens aproximam-se dos relatos de viagens, estilo comum na Europa e que ganhou mais força com os descobrimentos; algumas características importantes, porém, os afastam. D iferente dos relatos, os produtos das viagens não apresentavam uma narrativa na primeira pessoa, nem se ocupavam em relatar uma aventura em terras estrangeiras. Ambos eram compostos por material proveniente da experiência das viagens e admitiam o recurso da compilação de dados, sempre que fosse necessário, sem nenhum comprometimento do resultado final. ${ }^{20}$

Escrito aproximadamentecinqüenta anos depois da carta de N óbrega, em epígrafe, o trecho de Fernão C ardim indica esse processo contínuo de acumulação de conhecimento controlado pelos jesuítas: 
$\mathrm{N}$ ana - essa erva é muito comum, parece-secom a erva babosa, e assim tem as folhas, mas não tão grossas e todas em redondo estão cheia de uns bicos muito cruéis; no meio dessa erva nasce uma fruta como pinha, toda cheia de flores de várias cores muito formosas (...), a fruta é muito cheirosa, gostosa, euma das boas do mundo, muito cheia de sumo egostoso, etem sabor de melão ainda que melhor e mais cheiroso, eboa para doentes de pedra, e para febres muito prejudicial. (...) também se fazem em conserva, e cruas desenjoam muito no mar, e pela manhã com vinho são medicinais. ${ }^{21}$

É oportuno registrar que o procedimento descritivo de Cardim era um padrão comum presenteem textos científicos da época. A organização dos capítulos na obra de C ardim revela a preocupação em ordenar o conhecimento adquirido sobre o $\mathrm{N}$ ovo M undo. Particularmente no que se refere às plantas, está assim dividido: "D as árvores que dão fruto", "D as árvores que servem para medicinas", "D os óleos que usam os Í ndios para se untarem", "D as árvores que têm água”, "D as árvores que servem para madeira", "D as ervas que dão fruto e se comem" e "D as ervas que servem para mezinhas". Além dos dois capítulos que tratam das propriedades terapêuticas das espécies, o missionário - que serviu durante muito tempo e morreu na América portuguesa - não deixou de ressaltar o interesse terapêutico de cada uma delas.

A classificação dos produtos naturais era sempre feita levando em consideração o proveito dos diversos objetos para a vida humana. Esta hierarquia encontra justificativa filosófica no aristotelismo ainda bastante influente durante o século XVII. D e acordo com a concepção organicista e hierárquica do universo, as plantas existiam em função dos animais, e estes, em função dos homens. A mesma perspectiva estava presente nas interpretações teológicas feitas a partir do livro do G ênesis, onde se aprende que D eus colocou no jardim do Éden os meios de que os homens necessitavam para sobreviver. ${ }^{22}$

As virtudes de cada produto da natureza americana elucidadas pelos observadores, sejam eles missionários ou naturalistas, expressa a atitude de "descobrir" o lugar de cada um desses objetos dentro de uma ordem universalista, hierárquica e antropocêntrica. A medicina do século XVII não rompera ainda com a tradição aristotélica, eclassificar pela forma era identificar possíveis correspondências entre os objetos distribuídos por D eus 
sobre a Terra. Essa perspectiva ajuda a entender uma cultura que produz descrições minuciosas das coisas e ao mesmo tempo aproxima objetos diferentes pelo critério morfológico enão estrutural. ${ }^{23}$

A sistematização desse conhecimento era também elaborada a partir deuma prática ede referenciaisteóricos presentes na arte médica de então. D esde o C oncílio deTrento os padres da Companhia de Jesus foram proibidos de adotar práticas que implicassem na violação do corpo humano e que colocassem a vida do indivíduo em risco. A flebotomia, por exemplo, gerou entre os padres casos de consciência. Entretanto, pelas condições da América portuguesa e tendo os missionários assumido o papel de médicos, os padres acabaram conseguindo permissão para realizar tal intervenção, porém, apenas nos casos mais urgentes.

A flebotomia (ou sangria) difundiu-senaAmérica portuguesa em geral. O s padres e responsáveis pelo cuidado médico nos recintos pertencentes aos inacianos também recorreram freqüentemente à flebotomia. Entre os itens adquiridos para o Engenho Sergipe- pertencente aos jesuítas esituado na Bahia - ao lado de ervas e animais especificamente comprados para os "doentes" e de "utensílios para botica", havia o pedido de uma "lanceta para sangrar". ${ }^{24} \mathrm{~A}$ Colleção das Receitas, supracitada, contém uma gravura detalhada do sistema venal do corpo humano acompanhada de legenda indicando os lugares precisos para a operação, reduzindo, desta forma, os riscos fatais. 25

H á vários indícios de que a tradição hipocrática e galênica exerceu influência na medicina praticada pel os missionários da Companhia de Jesus. D eacordo com esse referencial, a intervenção do médico dava-se através de uma terapêutica que visava restabelecer o equilíbrio entre a tempe ratura do corpo humano edo meio ambiente, expulsando os humores que eventualmente estivessem provocando a anomalia. D esta forma, purgas e sangrias eram procedimentos comuns. Vale lembrar que ao descrever as árvores úteis para a medicina, Anchieta el ege apenas aquelas "que são proveitosas como purgantes". ${ }^{26}$

Segundo a tradição hipocrática, um dosfatores queinfluenciariam os humores era a ação da temperatura, e, por conseguinte, a saúde - física e moral - seria mantida por um equilíbrio entrea temperatura ambiente (ar, água e lugar) e a temperatura do corpo humano. $\mathrm{D}$ aí a crença de que 0 
clima exercia uma influência direta no ser humano, inclusive agindo sobre o seu intelecto. As doenças, assim como os homens, variam deacordo com o clima e o lugar, conforme ensinou $\mathrm{H}$ ipócrates

0 médico, instruído sobre a maior parte destas questões, todas se possível, (os ventos, as águas, a temperatura do sol, o solo e gênero de vida), ao chegar e uma cidade desconhecida, não ignorará nem as doenças locais, nem a natureza das doenças gerais, de tal modo que elenão hesitaráquanto ao tratamento a prescrever, nem cometerá os erros nos quais incorreria aqueleque não tivesseaprofundado anteriormente o estudo dessas questões essenciais. ${ }^{27}$

Para tratar de concepções médicas compartilhadas pel os missionários, um livro manuscrito guardado na Biblioteca $\mathrm{N}$ acional do Rio de Janeiro, recém localizado, édegrandevalor para nosso trabalho: Curiosidad un libro de medicina escrito por los jesuítas en las missiones del Paraguay, $1580 .{ }^{28}$

0 livro, dedicado à "sereníssima reyna de losangeles M aria santissima, y señora $\mathrm{N}$ ra de las D olores" se apresentava como uma obra que pretendia organizar o conhecimento médico a fim de auxiliar aqueles que praticavam a cura naquelas terras "distantes". No prólogo ao leitor podemos perceber vestígios que indicam a concepção que o autor anônimo tinha da arte médica. Acima dos sábios da antigüidade, D eus aparecia como o verdadeiro C riador da M edicina, fato que os "grandes estudiosos gregos e latinos", também consideraram. M esmo sendo D eus o principal Autor, o escritor do manuscrito não deixou de valorizar o papel do "sábio", pois a sabedoria era uma qualidade quediferenciava al gunshomens, uma vez que estes conseguiam "descobrir as virtudes escondidas" nos produtos da natureza: metais, pedras, animais e plantas. ${ }^{29}$ Era papel do sábio desvendar as virtudes dos produtos "oferecidos" pelo "G rande Arquiteto", ou pela “Divina Bondade" ao homem, no sentido de manter o seu bem estar naTerra. $H$ á também indícios de que o "sábio" identificava-se com a medicina hipocrática, pois as qualidades queelegeu como dignas de observação em cada objeto natural eram: "calor", "umidade", "frieza" e "secura". Esta relação entre 0 sujeito e o conhecimento que transparece através do jogo de correspondência entre o C riador e os objetos naturais, somada à idéia de que o sábio era um homem dotado de virtude especial que o distinguia dos demais - justamente por ter acesso aos segredos divinos escondidos nas coisas - aponta para uma perspectiva do conhecimento como revelação, 
presente na tradição hermética e mágica ainda vigente nos meios intelectuais europeus do século XVII.

0 documento acima mencionado foi catalogado como Curiosi dad un libro de medicina escrito por los jesuítas en las misiones del Paraguay, 1580. Q uem o catal ogou pareceter tido a mesma sen sação de "curiosidade" diante do conteúdo dos escritos ali contidos: Q uem de fato escreveu? Por que escreveu? Q ual o sentido de uma obra manuscrita de medicina nas missões do Paraguai?

0 estado físico do documento é relativamente bom. Escrito em espanhol, a maior parte é legível, porém faltam as páginas iniciais e finais, 0 que justifica a ausência do nome do autor. Entretanto, o autor anônimo oferece algumas pistas: declara ter servido durante 30 anos como médico no Colégio de M adri, e, ao longo da obra, referese a lugares por onde provavelmente passou: Colégio de Córdoba na Província de Tucumán e Colégio de Assunção. A expressão "en estes paises del Paraguay" aparece em várias passagens, assim como a expressão "en estas santas misiones" em que o autor se refere a Paraná, U ruguai, São Borja e São Gabriel e finalmente, no "livro segundo", o autor reuniu informações "D e las yerbas, y raízes medicinales de estas misiones, y Paraguay, con algunas del Brasil, y Provincia de Chile".

As referências toponímicas das missões que aparecem na obra nos levam imediatamente a rejeitar a data que aparece na classificação do documento: 1580. N este momento, tais missões não tinham sido criadas pela Companhia de Jesus. A penas em 1594 foi fundada a residência do Colégio de Assunção, e treze anos depois foi estabelecida a província jesuítica do Paraguai, subordinada à do Peru, deondepartiram osmissionários para iniciar o trabalho de conversão dos índios guaranis. Em Buenos Aires a chegada dos inacianos remonta ao ano de 1587, sendo a residência de Córdoba, em Tucuman, erguida em 1599. As reduções do Guairá, Paraná e U ruguai foram fundadas depois de 1615, momento em que os jesuítas assumiram definitivamente a defesa dos índios daquela região.

É oportuno lembrar que o governo do Paraguai tinha jurisdição sobre regiões que hojefazem parte do Brasil, daArgentina, do U ruguai eda Bolívia. Ao norte, a área era limitada pela capitania de São V icente, ao sul pelo Rio da Prata, a leste pelo 0 ceano Atlântico ea oeste pela Província de Tucumán. ${ }^{30}$ 
Provavelmente 0 autor anônimo realizou viagens ao interior dessa região e manteve contato com missionários ligados à Província Jesuítica do Brasil. D esde 1553, com a fundação do Colégio dos M eninos deJ esus, em São Vicente, os missionários realizavam expedições pelo litoral e interior com o objetivo de fundar missões reunindo índios guaranis. D o Rio de Janeiro, por exemplo, os padres J oão de Almeida e Afonso Gago realizaram uma viagem até o litoral de Santa $C$ atarina, de onde investiram na criação de al deias no interior. M esmo com o fracasso da investida, reuniram índios e os levaram para São Paulo, criando a aldeia de Barueri. ${ }^{31}$

Diante dessas ligações, não éde se estranhar que os produtos mencionados na obra, não fossem apenas os nativos daquela região da América. 0 autor anônimo se dedica, inclusive, a especificar o uso da pimenta, do cravo, da noz moscada e da canela, entre outras especiarias, que deveriam ser cultivadas com a finalidade de se extrair delas, as virtudes medicinais. Em várias passagens do manuscrito, 0 autor deixa clara sua intenção de passar conhecimentos àqueles que futuramente viessem a exercer 0 ofício de médico nas missões, provavelmente um seu confrade, que deveria se responsabilizar pelo cultivo das espécies medicinais mais úteis.

A cosmopolitização das práticas médicas era acompanhada por um processo de experimentação, cultivo e disseminação de plantas. O s jesuítas, conforme apontou Russel-Wood, real izaram a diáspora de produtos naturais no âmbito do império português, o que também pode ser verificado no interior do continente americano, pois, como foi apontado acima, havia troca de experiências e de informações entre os missionários que viajavam por esta vasta região. 0 autor anônimo falainclusivedas virtudes do cacau utilizado nas missões do sul e originário da região do G rão-Pará. ${ }^{32}$ Além disso, registra o uso do óleo de Copayba nos quatro continentes: "el bal samo deC opaybaes oy mui conocido y usado por toda laEuropa, Africa y America, u con gran estima e subido precio en el Japon, y C hina". ${ }^{33}$

0 autor anônimo parece ter conhecido as descrições do maracujá, particularmenteaquela consagrada por Frei V icentedo Salvador, pois quando trata em seu texto de "la granadila", expõe minuciosamente a flor da paixão associada à saga e aos mistérios de C risto. Ao tratar das qualidades da erva mate, 0 autor anônimo faz alusão ao mito de São Tomé, que, segundo Sérgio Buarque de $\mathrm{H}$ olanda, ${ }^{34}$ chegou à América espanhola através 
dos missionários jesuítas da Província do Brasil que penetraram o continenteamericano em busca dealmas: “... layerba (...) bien enbebida en agua tienepor tradicion antigua en estes paises del Paraguay, y misionesla enseño Santo Thome a los Indios."

Além das trocas de informações, havia práticas comuns nas reduções indígenas daAmérica espanhola edaAmérica portuguesa. Em análise sobreas missões do Itatim, R egina G adel ha afirma que "os jesuítas tudo faziam para alimentar a confiança dos índios. N as aldeias tratavam os enfermos, e se desdobravam em cuidados com as crianças". ${ }^{36} 0$ papel de médico desempenhado pel os padres era assinal ado também nos textos onde os missionários registravam as suas ações, como por exemplo num "informe sobre a fundação das reduções do Guairá feita a pedido do superior Pe. Joseph Cataldino", datada de Santa Fé, em 2/11/1614.

... onde se faz grandíssimo fruto, com su doctrina de vida, y costumbres, y bien exemplo quetienen, y enseñam a los natural es de aquellas provincias y en ellas trazen gran servo a dios nro señor y a su magd y a las almas (...) y curandoles sus enfermidades com mucho amor y caridad. ${ }^{37}$

A região era subordinada ao Colégio deAssunção, no Paraguai. 0 papel da cura era também estratégico nessa parte da América, o que já responde a uma das questões colocadas no início: a importância de uma obra médica nas missões, como coloca o autor anônimo no prólogo ao leitor, era a de auxiliar àqueles que viviam nas missões, isolados, longe das boticas e dos médicos doutos.

A estrutura do texto émuito próxima a de uma obra editada. N o formato de um livro, o manuscrito está organizado nas seguintes partes: dedicatória, prólogo ao leitor, advertências ao leitor, descrições das plantas acompanhadas de seususos, e um índice quetraz o nome das espécies descritas em espanhol, tupi e guarani. A preocupação em usar as três línguas parece maisum indício de que o conhecimento sobre os usos terapêuticos das plantas circulava entre os missionários no interior do continente americano.

O livro se apresentava como uma obra que pretendia organizar o conhecimento em "estas tierras tan pobres de medicosy boticas". U ma hipóteseéque o texto tenha sido elaborado justamente com essa finalidade: servir de guia para ser usado em lugares distantes das cidades, como por exem- 
plo, os missionários das reduções, pois sabemos que os Colégios, situados nos centros urbanos coloniais, eram dotados de botica. Além disso, o autor anônimo não registrou nenhum medicamento composto, mas se ocupou apenas de registrar os símplices, como já dissemos, medicamentos feitos utilizando apenas uma substância.

Acredito que esse manuscrito tenha sido elaborado na segunda metade do século XVII ou no início do seguinte, pois o conteúdo do saber médico e a forma pela qual se classificam as plantas, são peculiares àquele período. Pelas referências que o autor anônimo faz no decorrer do texto, pode-se deduzir que ele, além de jesuíta, (como já dissemos, serviu no Colégio de M adri), era médico e conhecia os escritos de outros médicos de sua época. Entre os médicos citados pelo autor destaco a referência a G uiIherme Piso. ${ }^{38}$

0 autor anônimo identificava-se com $\mathrm{G}$ aleno, a quem considerava "filósofo e príncipe da medicina". Seguindo seus ensinamentos, entende que "curar consiste en cierta qualidad, cierta cantidad, y cierto modo de aplicacion". A identificação com o pensamento de $G$ aleno confirma a idéia de que a medicina hipocrática oferecia um suporte para a prática médica nos trópicos. Galeno éherdeiro das tradições filosóficas emédicas da G récia, em seustextoshá referências aos trabal hos deH ipócrates. ${ }^{39}$ Tudo isto aponta para a possibilidade do autor anônimo ser alguém ligado à tradição ibérica, um jesuíta, por exemplo, pois nos currículos de medicina em Coimbra e Évora além dos textos de $\mathrm{H}$ ipócrates, os de $\mathrm{G}$ aleno eram também lidos pelos estudantes ${ }^{40}$

No trecho do manuscrito cujo título é "advertências ao leitor", percebemos o esforço do autor em orientar aquele que irá manipular as plantas para preparar os símplices. Era imprescindível saber plantar e colher no momento certo; a época correta era indicada de acordo com o temperamento da planta - quente ou fria - caso contrário, o seu consumo pode ser danoso ou sem efeito. 0 local escolhido para o cultivo das plantas era também relevante, principalmente para protegêlas dos ventos frios e secos e do calor, elementos que poderiam prejudicar suas virtudes; a posição da lua era importante. Um outro indício da concepção médica do autor anônimo é o fato de ele relacionar um determinado produto ao Sol, a $M$ arte ou a Lua, de acordo com seus respectivostemperamentos. Aqui, maisuma 
vez pode-se perceber a ligação do autor com uma concepção de mundo corrente no século XVII e que era compartilhada por sábios, entre eles os médicos.

A percepção consubstancial do universo, presente no pensamento aristotélico, fazia com que todos os elementos mantivessem relações entre si. A través das qualidades essenciais dos elementos (quente, frio, seco eúmido) e da morfologia os sábios estabeleciam um complexo jogo de correspondência capaz de reunir todo o U niverso: os corpos celestes, os homens, as plantas, os animais, além das substâncias minerais. As doenças também eram entendidas e descritas a partir de suas qual idades, conforme a teoria dos humores. Essa lógica confere uma racionalidade aos procedimentos médicos, garantindo a aplicação correta das substâncias, fazendo com que suas virtudes terapêuticas ajam sobre os corpos enfermos. 0 autor anônimo chega a citar Plínio, que, acreditava que um corpo atuava sobre outro a partir de uma causa essencial. Por exemplo, "uma semente banhada em azeite, em vinho ou plantada em certos dias da lua vai germinar e crescer incondicional mente de maneira satisfatória" . ${ }^{41}$

Finalmente, a forma pela qual o autor anônimo descreve as plantas é recorrente entre os séculos XVI eXVII. Em primeiro lugar fornece o seu nome, normalmente em espanhol, guarani e tupi. D epois ressalta os aspectos morfológicos, sempre, que possível, aproximando de al guma espécie européia. D epois segue apontando suas virtudes terapêuticas, sempre valorizando as qualidades de quente, fria, úmida ou seca; estas podem ser percebidas pelo médico através dos sentidos: o paladar ou o olfato identificando sabores e cheiros que variam entre doce, ácido, insosso ou sal gado.

Se podemos perceber a presença de referenciais da cultura erudita européia orientando as ações e procedimentos dos médicos jesuítas, não são menos presentes no registro do autor anônimo, algumas práticas locais. Percebemos que observar a forma pela qual os indígenas usavam determinadas plantas era um procedimento comum. Vale sublinhar porém, que o esforço dos registros era justamente o de integrar e explicar o efeito de uma terapêutica a partir de referenciais consagrados pela cultura científica européia.

Como vimos, asidéias dePlínio, Galeno eH ipócrates circularam entre os missionários jesuítas na América portuguesa. O s médicos e farmacêuti- 
cos ligados à Companhia de Jesus, responsáveis pela orientação das práticas médicas nos Colégios, seguiram al gumas proposições e concepções desses sábios ao elaborarem suas fórmulas e receitas. É oportuno informar que havia, no Colégio do Rio de Janeiro, um exemplar da $\mathrm{H}$ istória $\mathrm{N}$ atural de Plínio. ${ }^{42}$

A cura, inserida no contexto das missões, para além da caridade, relacionava-se ao esforço de conversão do gentio, o que reforça nosso argumento de que a cura fazia parte das estratégias jesuíticas para a ocupação do território americano. 0 utro ponto levantado foi o de que o conhecimento médico era elaborado de forma sistemática e influenciado pela medicina européia de então.

0 saber durante a época Barroca estaria articulado à premissa deatingir e controlar os homens, tanto no plano racional quanto emocional, restringindo-Ihes as liberdades. Entre os saberes sobre os homens, destacavasea medicina, que tratava não só de entender e intervir no funcionamento do corpo, mas sobretudo nas paixões enos impulsos humanos. N o conhecimento médico da época, o temperamento do corpo humano relacionava-se ao temperamento da alma. José Antonio $M$ aravall ao definir a cultura barroca como um conceito de época, remetendo para a Europa do século XVII tendo seus desdobramentos na América, afirma que esta é marcada pelo esforço por parte do Estado - entre outras instituições - em afirmar seu poder sobre os homens. Segundo M aravall, o pensamento barroco não é racionalista,

mas aparentado com o pensamento racionalista; serve-se de processos parcial menteracional izados, das criações técnicas e calculadas que daí derivam, para alcançar o domínio prático da realidade humana e social sobre a qual quer operar. ${ }^{43}$

N esse sentido, podemos afirmar que entre as estratégias jesuíticas de conversão, o saber médico estaria relacionado às intenções de cooptar 0 corpo e a alma do gentio, isto é, ao cuidado corporal soma-se o espiritual. ${ }^{44}$ 


\section{Bibliografia}

AM ARO , Ana M aria. Influência da farmacopéia chinesa no receituário das boticas da Companhia de Jesus. In: Revista de Cultura. M acau, v. 30, 1997.

AT RAN , Scott. CognitiveFoundations of N atural H istory; Toward an Anthropology of Science. Cambridge: U nivesristy Press, 1990.

BARRETO, Luis Filipe. Caminhos do saber no renascimento português: estudos de história e teoria da cultura. Porto: Imprensa N acional Casa de M oeda, 1987.

BICALH O , FRAGOSO \& GOUVÊA (O rgs.). 0 antigo regimenostrópicos. Rio de Janeiro: Civilização Brasileira, 2001.

CAM EN IETZKY, Carlos Ziller. A cruz e a luneta. Ciência e religião na europa moderna. Rio de Janeiro: Access, 2000.

CIPO LLA, Carlo. Faith, Reason and the Plague in Seventeenth Century Tuscany, N ova lorque: W. W. Norton and Company, 1979.

DEAN , Warren. A botânica ea política imperialista de Portugal. In: EstudosH istóricos. Rio de Janeiro, v. 4, n. 8, pp. 216-228, 1991.

D O M IN GUES, Ângela. Para um melhor conhecimento dos domínios col oniais: A constitui ção de redes de informação no I mpério português em finais do setecentos. In: H istória, ciência, saúde: manguinhos. Rio deJaneiro, v. VIII (suplemento), pp. 823838, 2001.

EISEN BERG , José. Asmi ssõesjesuíticase o pensamento político moderno. Belo H orizonte: UFM G, 2000.

FU N KEN ST EIN , Amos. T heology and theScientific Imagination: From theM iddle Ages to the Seventeenth Century. Princenton: U niversity Press, 1986.

GAD ELH A, Regina M aria F. Asmi ssões jesuíticas do itatim: estrutura sócio-econômica do Paraguai colonial - séculosXVI eXVII. Rio de Janeiro: Paz eTerra, 1980. GESTEIRA, H eloisa. 0 teatro dascoisasnaturais, conheci emento edominação neerIandesa no Brasil. Tese de D outorado. N iterói: D epartamento de H istória, U niversidade Federal Fluminense, 2001.

H O LAN D A, Sérgio Buarque de. Visão do paraíso. São Paulo: Brasiliense, 1992. LEITE, Serafim. História da Companhia de esus no Brasil. Tomo II (século XVI - A 0 bra). Rio de Janeiro: Civilização Brasileira, 1938.

- Serviços de saúde da Companhia de esus no Brasil. In: Brotéria, separata do v. IV, fasc. 4. Lisboa, abril de 1952. 
. Cartas dos primeirosjesuítas do Brasil. São Paulo: Comissão do IV Centenário da Cidade de São Paulo, v. 3.

LEN O BLE, Robert. História da idéa de natureza. Lisboa: Edições 70, 2002. M ARAVALL, JoséAntonio. A cultura do barroco. São Paulo: ED U SP, 1997. M AT TO S, Ilmar Rohloff de. 0 tempo Saquarema. São Paulo: HU CITEC, 1987. M ONTEIRO, John M anuel. Os negros da terra. São Paulo: Companhia das Le tras, 1994.

RAM A, Angel. A cidade das letras. São Paulo: Brasiliense, 1982.

RU SSEL-W O O D. U m mundo em movimento: os portugueses na África, Ásia e América (1415 - 1808). Lisboa: Difel, 1998.

\section{Notas}

${ }^{1}$ CIPO LLA, C arlo. Faith, Reason and the Plague in Seventeenth Century Tuscany. N ova Iorque: W. W. N orton and Company, 1979.

${ }^{2}$ LEN O BLE, Robert. H istória da I déia de N atureza. Lisboa: Edições 70, 2002. p. 49.

${ }^{3}$ FU N KEN ST EIN , Amos. Theology and theScientific Imagination: From theM iddleAges to theSeventeenth Century. Princenton: Princeton U niversity Press, 1986. CAM EN IET ZKY, CarlosZiller. A cruz ea luneta. Ciência ereligião na europa moderna. Rio deJ aneiro: Access, 2000.

${ }^{4}$ BARRETO, LuisFilipe. Caminhosdo saber no renascimento português estudos dehistória eteoria da cultura. Porto: Imprensa N acional Casa de M oeda, 1987. p. 111.

${ }^{5}$ BARRETO, Luis Filipe, op. cit.

${ }^{6}$ Cf. RU SSEL-W O O D. U m mundo em movimento: os portugueses na África, Ásia eAmé rica (1415 - 1808). Lisboa: D ifel, 1998. Especialmente o capítulo “D ifusão de Espécimes da Flora e da Fauna"; D EAN , Warren. A botânica ea política imperial ista de Portugal. Estudos H istóricos, Rio de Janeiro, v. 4, n. 8, pp. 216 - 228, 1991. D O M IN GUES, Ângela. Para um melhor conhecimento dos domínios coloniais: a constituição de redes de informação no Império português em finais do setecentos. H istória, ciência, saúde: M anguinhos, Rio de Janeiro, v. VIII (suplemento), pp. 823-838, 2001.

${ }^{7}$ M AT T O S, IImar Rohloff deM attos. 0 tempo Saquarema. São Paulo: H U CIT EC , 1987. Para o conceito de cidade colonial desenvolvido pelo autor conferir especialmente o primeiro capítulo.

${ }^{8}$ Cf. RAM A, Angel. A cidade dasletras. São Paulo: Brasiliense, 1982.

${ }^{9}$ GUERREIRO , Fernão. Relação anual das coisas que fizeram os padres da Companhia de Jesus nas suas mi ssões do Japão, China, Catai o... e Brasil nos anos de 1600 - 1603. Évora, 1930, p. 375. 


\section{2 - Heloisa M eireles G esteira}

${ }^{10}$ Livro deTombos das escrituras das cousas que pertencem ao C ollégio de São Sebastião da Companhia de Jesus no Rio de Janeiro. Rio de Janeiro: Anaisda Biblioteca Nacional, v. 82, 1962, pp. 27-28.

${ }^{11}$ As relações entrea coroa eos agentes coloniais podem ser aprofundadas em BICALH 0 , FRAGOSO \& GOUVÊA, (O rgs.). 0 antigo regimenostrópicos. Rio deJ aneiro: Civilização Brasileira, 2001.

${ }^{12}$ AN C H IETA, José. Q uadrimestre de maio a setembro de 1954, de Piratininga. In: Cartas. informaç̧ões fragmentoshistóricosesermões. Belo H orizonte: Itatiaia, São Paulo: ED U SP, 1988 , p. 52.

${ }^{13}$ EISEN BERG, José. Asmi ssões jesuíticas e o pensamento político moderno. Belo H orizonte: UFM G, 2000. p. 61.

${ }^{14}$ Idem, p. 80.

${ }^{15}$ O s compostos eram medicamentos elaborados a partir de várias substâncias reunidas numa só receita. Estes se diferenciavam dos símplices, receitas feitas com uma substância que poderia ser preparada com água, licor, vinho, aguardente ou azeite.

${ }^{16}$ VASC O N CELOS, Simão de. Crônica da Companhia de Jesus. Petrópolis: Vozes, 1977, 2 volumes, p. 107.

${ }^{17}$ LEITE, Serafim. História da Companhia de Jesus no Brasil. Tomo II (século XVI - A O bra). Rio de Janeiro: Civilização Brasileira, 1938. p. 285.

${ }^{18} \mathrm{C}$ f. LEITE, Serafim. Serviços de saúde da Companhia deJ esusno Brasil. Brotéria, separata do v. IV, Lisboa, fasc. 4, abril de 1952. Ver ainda artigo de AM ARO, Ana M aria. Influência da farmacopéia chinesa no receituário das boticas da Companhia de Jesus. Re vista de Cultura. M acau, v. 30, 1997, pp. 53-68.

${ }^{19} \mathrm{C}$ arta do P. M anuel da N óbrega ao P. Francisco H enriques. In: LEITE, Serarifim. Cartas dos primei ros J esuítas do Brasil. São Paulo: Comissão do IV Centenário da Cidade de São Paulo, v. 3, pp. 350-351.

${ }^{20}$ G EST EIRA, H eloisa. 0 Teatro das coisas naturais, conheciemento e dominação neerlandesa no Brasil. Tese de D outorado. N iterói: D epartamento de H istória, U niversidade Federal Fluminense, 2001. p. 38.

${ }^{21}$ C ARD IM , Fernão. Tratados da terra e do clima do B rasil. Belo H orizonte: Itatiaia, São Paulo: ED USP, 1980. p. 42.

${ }^{22}$ AT RAN , Scot. Cognitive Foundations of N atural H istory. Toward an Anthropology of Science. Cambridge:U niversity Press, 1990.

${ }^{23}$ LEN O BLE, Robert, op. cit.

${ }^{24}$ Livro de receita e despesa do Engenho de Ceregipe, de 21 de junho de 1622 a 21 de maio de 1633. Biblioteca N acional do Rio de Janeiro, M ss II , 33, 14, 39 (cópia), p. 143.

${ }^{25}$ LEITE, Serafim. História da Companhia de Jesus no Brasil. Tomo II (século XVI - A O bra). Rio de Janeiro: C ivilização Brasileira, 1938. p. 575. 
${ }^{26}$ AN C H IETA, José. Cartas informações, fragmentos históricos esermões. Belo H orizonte: Itatiaia, São Paulo, ED USP, 1988. p. 137.

${ }^{27} \mathrm{H}$ ipócrates. LesAirs, leseaux eleslieux. Traduzido do grego ecomentado por Émile Littré, Paris, Arléa. 1995. Trecho retirado da obra de GuilhermePiso, IndiaeU triusquerenaturalis et medica. Amstelodamis, apud Ludovicum et $D$ anielem Elzevirios, 1658. (tradução de M ario Lobo Leal, Piso, H istória N atural e M édica da Índia O cidental. Rio de Janeiro: M inistério da Educação e Cultura, Instituto N acional do Livro, 1957).

${ }^{28}$ Biblioteca $\mathrm{N}$ acional do Rio de Janeiro, Sessão de M anuscritos, Curiosidad un libro de medicina escrito por los jesuítas en las mi ssiones del Paraguay, 1580. Acredito ser este documento inédito pois até agora não encontrei referência ao mesmo em trabalhos sobre história da medicina e nem tampouco nas obras especializadas na documentação jesuítica tais como os de Sommervogel e Serafim Leite.

${ }^{29}$ Anônimo, U m libro de medicina escrito... BN RJ, M ssI-15-02-26.

${ }^{30} \mathrm{~N}$ ão me deterei no processo de ocupação da área nem tampouco nas tensões entre os missionários jesuítas - espanhóis e portugueses -, os col onos de origem espanhola e lusa, a as autoridades locais que disputavam a ocupação da região e o controle sobre a mão de obra indígena. Vale lembrar ainda que o período de ocupação dessa área coincidiu com a época da U nião I bérica, 1580/1640. Cf. GAD ELH A, Regina M aria F. Asmi ssõesjesuíticas do Itatim: estrutura sócio-econômica do Paraguai colonial - séculosXVI eXVII. Rio deJ aneiro: Paz eTerra, 1980; M O N T EIRO, John M anuel. O snegros da terra. São Paulo: Companhia das Letras, 1994.

${ }^{31}$ GAD ELH A, Regina, op. cit.

${ }^{32}$ RU SSEL-W O O D. U m mundo em movimento. Lisboa: D ifel, pp. 235-238.

${ }^{33}$ Anônimo, p. 10.

${ }^{34}$ H O LAN D A, Sérgio Buarque de. Visão do paraíso. São Paulo:Brasiliense, 1992.

${ }^{35}$ Anônimo, p. 15.

${ }^{36}$ GAD ELH A, Regina M aria F, op. cit., p. 219.

${ }^{37}$ Jesuítas ebandeirantes no G uairá, 1594/1640. M anuscritos da Coleção deAngelis. Introdução, notas e glossário de Jaime Cortesão. R io de Janeiro: Anais da Biblioteca N acional, 1951.

${ }^{38}$ Guilherme Piso: médico neerlandês que acompanhou $\mathrm{M}$ aurício de $\mathrm{N}$ assau durante 0 domínio holandês no Brasil. É autor deH istória N atural do Brasil (1648), junto com Jorge $M$ arcgrave, e de H istória N atural e M édica dasíndias 0 cidentais (1658). A referência aos trabal hos de Piso é mais um dado que aponta para o fato de que o manuscrito que analisamos não data de 1580.

${ }^{39}$ G ALEN O . Selected Works. O xford: U niversity Press, 1997. Tradução, introdução enotas por P. N. Singer.

${ }^{40} \mathrm{ABREU}$, Eduardo. A Physicatura-mor o C irurgião mor dos Exércitos no Reino de Portugal e Estado do Brasil. Rio de Janeiro: RIH G B, v. 63, 1900, pp. 154-306. 
${ }^{41}$ Plínio citado por Robert Lenoble. H isória da idéa denatureza. Lisboa: Edições 70, p. 163. ${ }^{42}$ Auto de inventário e avaliação dos livros achados no Colégio do Rio de Janeiro e Seqüestrados em 1775. Rio de Janeiro: RIH GB, v. 301, out/dez, 1973, p. 240.

${ }^{43}$ M ARAVALL, José Antonio. A cultura do barroco. São Paulo: ED U SP, 1997. p. 130.

${ }^{44}$ Este artigo é fruto dos primeiros resultados al cançados durante a pesquisa M edicina Brasiliensi - conhecimento e colonização da América nos séculos XVI eXVII. 0 trabaIho conta com o apoio do CN Pq através de uma Bolsa Recém D outor eestá sendo desenvolvido junto ao D epartamento de H istória da U niversidade Federal do Rio de Janeiro.

\section{Resumo}

0 artigo privilegiará a análise do manuscrito apócrifo Curiosidad un libro demedicina escrito por losjesuítas en las mis ones del Paraguay, 1580, recentemente encontrado na Biblioteca $\mathrm{N}$ acional. $\mathrm{O}$ objetivo deste trabalho é demonstrar como havia uma relação orgânica entre a produção de conhecimento sobrea natureza e o processo de conquista da América durante os séculos XVI eXVII. A "botânica médica" aparece como um campo de saber privilegiado, pois esse conhecimento era realizado de forma sistematizada e, no caso específico da América portuguesa, controlado sobretudo por agentes sociais interessados na edificação de uma sociedade no $\mathrm{N}$ ovo M undo, destacando-se os missionários da Companhia de Jesus. N um primeiro momento elucidaremoso papel da cura no projeto jesuítico deconquista da América. Finalmente, analisaremos as concepções médicas compartilhadas pelos jesuítas. 0 registro das informações sobreas virtudes das plantas e de algumas partes de animais para uso medicinal foi feito de maneira sistemática, o que levou os jesuítas a acumularem um saber importante para a manutenção da sociedade colonial.

Pal avras-chave: natureza; história social da ciência; colonização

\section{Abstract}

This article is about a manuscript recentely found in the $\mathrm{N}$ ational Library of Rio de Janeiro, Curiosidad un libro de medicina escrito por los jesuítas en las mis ones del Paraguay, 1580. The main subject of the paper is to show how the studies and observations of the $\mathrm{N}$ ature in the $\mathrm{N}$ ew World were related with the process of conquest of America during the 16th and 17th 
century. The studies of medical botany are a good example because this knowledge was made in an organized way and controlled by the Jesuits in thePortuguese colonies in America. This articleconcernson the roll played by the healing in the Jesuitical project of conquest, and also the medical theories applied by them.

Key-words: nature; social history of science; colonization 